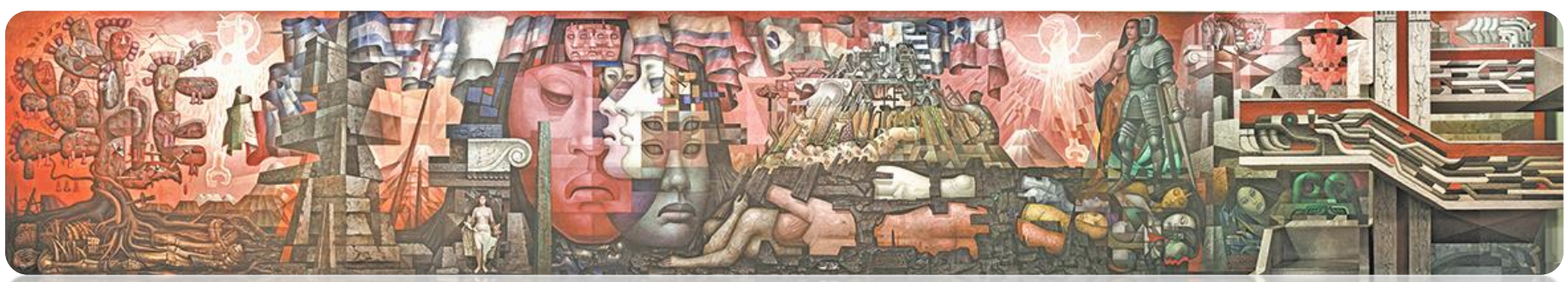

Rev. Hist., N²8, vol. 2, Julio-Diciembre 2021: 473-494

ISSN 0717-8832

https://doi.org/10.29393/RH28-40IAAA10040

\title{
El ideal de amor en Lesbos, a partir de Safo y Alceo
}

The ideal of love on Lesbos, from Sappho and Alcaeus

Alejandro Andrés Saavedra Sanhueza*

\begin{abstract}
RESUMEN
El presente artículo, desarrolla el ideal de amor de pareja en el plano del horizonte onírico en Lesbos (finales siglos VII e inicios del VI a. C.), a través del estudio de los poetas Safo y Alceo. En este, se buscó determinar cómo los ideales aristocráticos vinculados al agonismo y el contexto sociohistórico participan en la conformación y elevación del "amor" al campo de los anhelos, poniendo como base la dialéctica entre philía y éros. El tema es abordado desde un enfoque vinculado a la historia de las emociones y el erotismo, visualizándose una preeminencia de las relaciones asimétricas, las que encuentran su legitimación en el actuar de las divinidades.
\end{abstract}

Palabras claves: Safo, Alceo, amor, philía, éros, horizonte onírico.

\section{ABSTRACT}

This article develops the idea of couple's love in the horizon dreamlike in Lesbos, at the ends of 7th and early 6th B.C. Through the study of the poets Sappho and Alcaeus. In this it was sought how aristocratic ideas are connected to the agonism within its own social historic context, they participate in the conformation and elevation of "Love" to the field of emotions and yearnings, putting as a basis the dialectic between philía and éros. The subject is approach focusing bonded with the history of emotions and erotism, visualizing predominance of asymmetric relations, which could be found their legitimacy in the actions of divinities.

\footnotetext{
* Magister en Historia y estudiante de Doctorado, Universidad de Concepción, Chile. Académico en la Universidad Adventista de Chile, Chillán. Integrante del "Grupo de Estudios del Mediterráneo Antiguo Universidad de Concepción". ORCID: ORCID: https://orcid.org/0000-0003-1700-8896. Correo electrónico: alesaavedra@udec.cl, alejandrosaavedra@unach.cl.
} 
Key words: Sappho, Alcaeus, Love, philía, éros, horizon of dreamlike.

Recibido: abril 2021

Aceptado: agosto 2021

\section{Introducción}

El tratar el tema del "amor" ya supone un desafío mayúsculo, debido a las subjetividades y suspicacias que despierta de forma inmediata, como también a la diversidad expresiva de este. En la actualidad se tiende a separar el tema del amor de pareja en dos: el llamado "amor romántico" y el "amor maduro", ninguno de los cuales se condice claramente con la manera cómo los griegos de la época arcaica lo entendieron. El problema antes planteado se multiplica si nuestra meta es poder comprender el ideal de amor en la segunda época arcaica ${ }^{2}$, lo que exige un esfuerzo hermenéutico que implica la necesidad de proyectarse hacia aquella alteridad $^{3}$, sumergiéndonos en el mundo de la isla de Lesbos. Con el objeto de alcanzar aquel sentido interior como menciona Jean Grondin ${ }^{4}$, el artículo se centrará particularmente en Mitilene y en la vida de los poetas Safo y Alceo.

Habiendo consignado lo anterior, el presente trabajo busca poder determinar el ideal de amor en Lesbos en los siglos VII y VI a. C., en relación con los ideales aristocráticos de este lugar y período, que han quedado simbolizados en los escritos de los poetas líricos ${ }^{5}$ Safo y Alceo.

\footnotetext{
${ }^{1}$ En la actualidad se tiende a dividir el amor en dos categorías: el "amor romántico", entendido como un estado emocional, impulsivo, intenso y con gran fuerza dinámica. Algo incontrolable que libera rápidamente los deseos, véase, Elsner, Paulina; Montero, María; Reyes, Carmen y Zegers. 1993. Beatriz, La familia una aventura, Santiago, Universidad Católica de Chile. Además, se puede entender que el amor está compuesto por un triángulo que opera de manera simultánea, pero con alternancia de dominio de uno de los vértices según la etapa que se está viviendo. Las variables que representan cada vértice del ángulo son: la pasión, el compañerismo y la intimidad. Siendo el resultado de una construcción consciente e inconsciente que se da entre dos individuos. Véase. Sternberg, Robert. 2000. El triángulo del amor: intimidad, pasión y compromiso, Madrid, Paidós,

2 Según la clasificación de Alsina, José. 1983. Literatura Griega, Barcelona, Ariel. Tradicionalmente el académico español considera a la primera época arcaica con la épica siglos VIII e inicios del VII y la segunda con la lírica siglos VII y VI. Pese a esto tenemos claridad que la lírica se extendió mucho más allá de estas fronteras temporales, teniendo a grandes poetas líricos incluso en el siglo III a.C., pero su primacía como expresión artística y cultural en Grecia estuvieron en estos siglos para luego dar paso a la tragedia.

${ }^{3}$ Gadamer, Hans.1993. Verdad y Método, Salamanca, Sígueme, p. 316.

${ }^{4}$ Grondin, Jean. 1999. Introducción a la hermenéutica filosófica, Barcelona, Herder, p. 45.

${ }^{5}$ Cabe señalar que ya la clasificación de poetas líricos parece compleja, pero la mantendremos en este trabajo aun cuando algunos prefieran el apelativo de "mélicos", para nuestros poetas en cuestión. Para un tratamiento sobre este tema, véase: Torres, José, 2019. Introducción a la literatura griega antigua, Madrid, Síntesis, pp. 51-54. Ver también: García, Fernando. 2017. De hombres y dioses. Antología de poesía lírica griega antigua (siglo VII-V), Salamanca, Guillermo Escobar, pp. 9-25.
} 
El motivo de circunscribir el trabajo solo a estos poetas responde a que buscamos particularizar el estudio desde un enfoque que estriba entre la historia de las emociones, por un lado, y el erotismo, por otro. Para el primero (historia de las emociones), se seguirá el camino de la teoría de las "comunidades textuales" plateadas por Barbara Rosenwein", como también los trabajos del reconocido historiador clásico David Konstan, quien ha demostrado con creces la diferencia de connotación que puede tener una emoción en distintos periodos de la época antigua, e incluso en la misma civilización griega ${ }^{7}$. En cuanto al erotismo, se reconoce la dependencia para con el trabajo de Claude Calame: "Eros en la antigua Grecia" 8.

En congruencia con los enfoques planteados, se presenta como imprescindible acotar al espacio físico y temporal donde vieron su origen los poemas en estudio, con el objeto de poder historiarlos de manera adecuada. Con ello, no pretendo desconocer los estudios que buscan tener un mayor alcance, tanto espacial como temporal, pero bajo esa mirada es prudente tener el cuidado de no exacerbar las conclusiones ubicando las expresiones afectivas, en este caso el "amor", fuera del espacio territorial y espacial donde vieron la luz. En especial, considerando "que sentimos y nos emocionamos de acuerdo con el entorno en el que hemos nacido y en el que vivimos" ${ }^{\prime \prime}$. En este trabajo proponemos que, a través de los escritos de Safo y Alceo, se aprecian ideales vinculados al orgullo, la preeminencia, la superioridad, es decir, de carácter agonístico, que influirían en la conformación de relaciones asimétricas en el plano del horizonte onírico $^{10}$.

Hay que precisar que el concepto de horizonte onírico en Le Goff, hacía referencia a la imaginación que generaba en la cristiandad medieval, aquel lejano mundo oriental y que se

\footnotetext{
${ }^{6}$ Este enfoque considera que estos plexos textuales son medios de contactos emocionales, las que se pueden estudiar mediante un análisis del conjunto de conceptos vinculados a la emoción que se pretende descifrar Rosenwein, Bárbara. 20006. Emotional Communities in the Early Middle Ages, Ithaca, Cornell University Press.

7 Sobre la diferencia de énfasis de los celos entre Hera (en la épica homérica) y Medea (en la tragedia), Vid. Konstan, David. 2003. "Before jealousy", en Konstan, David and Rutter, Keith (edit.), Envy, Spite and jealousy, Edinburg, Edinburg University Press, pp. 7-27. En cuanto a la cólera en la antigüedad griega. Vid. Konstan, David. 2003. "Aristotle on anger and the emotions: The strategies of status", in Braund, Susanna and Most, Glenn W. (eds.), Ancient Anger: Perspectives from Homer to Galen, Yale Classical Studies 32, Cambridge, Cambridge University press, pp. 99-120. En cuanto a la piedad recomendamos Konstan, David. 2001. Pity transformed, London, Duckworth. En cuanto a la mirada de Konstan sobre las emociones en la antigüedad clásica, recomendamos la conferencia que brindó en la Universidad de la Sabana, el 18 de agosto de 2004, bajo el título: "Translating ancient emotions", publicada en Konstan, David. 2004. "Las emociones en la antigüedad griega", en Pensamiento y cultura, N 7 , Sabana, pp. 47-54.

${ }^{8}$ Calame, Claude. 2002. Eros en la antigua Grecia, Madrid, Akal.

${ }^{9}$ Camps, Victoria. 2011. El gobierno de las emociones, Barcelona, Herder, p. 29. Para un ejemplo de emociones circunscritas a contextos culturales vid., Lutz, Catherine. 1988. Unnaturale Emotions: Everyday Sentiments on a Micronesian Atoll and Their Challenge to Western Theory, Chicago, University of Chicago Press. En lo referido a la relación entre emociones y contexto histórico recomendamos revisar a Frevert, Ute, Emotions in History: Lost and Found, Central European University Press Budapest, 2011, pp. 31-32.

${ }^{10}$ Le Goff, Jacques. 1999. La civilización de Occidente Medieval, Barcelona, Paidós, pp. 119-120. Cfr. Ibid. 1883. Tiempo trabajo y cultura en Occidente medieval, Madrid, Taurus.
} 
trasformaba en el receptáculo de los sueños y deseos insatisfechos ${ }^{11}$. Para los usos de este estudio, el concepto toma distancia del componente de lejanía geográfica, posicionándose en el sentido psicológico del término. En otras palabras, pone su acento en las emociones, limitaciones, anhelos y sentimientos de los poetas no necesariamente materializados, los cuales, se han constituido socialmente en ese proceso de interacciones que se daban en el ambiente del simposio ${ }^{12}$, donde el "amor" ocupaba un lugar determinado, quedando como un testimonio valioso para su estudio e interpretación.

Por otra parte, para este trabajo se entiende el término "amor en su más amplio sentido, tanto si se lo relaciona con el sexo, la pornografía o la obscenidad, como si se le considera en su aspecto más espiritual y bellamente expresado"13.

Con el objeto de poder cumplir el objetivo trazado, el trabajo se abre inicialmente con un repaso por la vida de los poetas en estudio y las peripecias vividas en la singular Mitilene (isla de Lesbos) en la zona oriental del Egeo. Además de revisar de manera muy sucinta el juego

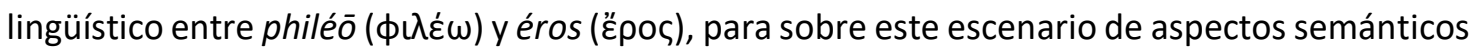
y socioculturales, interpretar desde una mirada de los arquetipos ${ }^{14}$, las expresiones contenidas en los fragmentos que nos han llegado.

Por motivos prácticos, se ha preferido la traducción de los poemas de Safo y Alceo presentes en la obra "Lírica griega arcaica, (poemas corales y monódicos 700-300 a.C.)", de la editorial Gredos. Si bien hay ediciones más nuevas ${ }^{15}$, la de Gredos es la más completa, además que mantiene el ordenamiento de los fragmentos realizada por Voigt, que permite seguir de mejor forma las citas.

\section{La figura de Safo y su contexto}

El recientemente desaparecido Helenista español Francisco Rodríguez Adrados, en el prólogo y notas introductorias que realiza a los fragmentos de la poetisa Safo, intenta poner en un plano más claro el actual conocimiento que se tiene de la poetisa de Lesbos. Es muy enfático en señalar que nuestro conocimiento de ella y de su obrar es menor de lo que aparentemente se puede observar. Menciona que ya en la antigüedad se había dado la situación de la "cuestión

\footnotetext{
${ }^{11}$ Le Goff, Jacques. 1999. La civilización, pp. 119. De toro, mencionó que esa Edad Media que nos describe Le Goff en su obra, era "donde caben los sueños, los temores, las aspiraciones y los demonios personales más íntimos" De Toro, José. 2016. "Apud indos ver perpetum. El extremo oriente durante la Edad Media: una revisión del horizonte onírico de Jacques Le Goff", en Revista de historia Universidad de Concepción, vol. 1, N²3, Concepción, pp. 85.

12 Ya sea en los círculos de varones en el caso de Alceo y de mujeres en el caso de Safo. Rodríguez, Francisco. 1981. El mundo de la lírica griega antigua, Madrid, Alianza, p. 87.

${ }^{13}$ Martínez, Marcos. 2010. Sófocles. Erotismo, Soledad, Tradición, Madrid, Clásicas, p. 37. Cfr. Ibid. 2012. "Erotismo en Homero (I)", en Cuadernos de Filología Clásica. Estudios griegos e indoeuropeos, № 22, Madrid, p. 54.

14 Jung, Carl. 2003. Arquetipos e inconsciente colectivo, Barcelona, Paidós, pp. 9-48.

${ }^{15}$ En los casos que se hizo uso de otra edición, se indican para conocimiento del lector.
} 
Sáfica" ${ }^{16}$, diversos relatos se cernían sobre ella, pero la mayoría de ellos gestados por interpretaciones inadecuadas y colmados por la tradición y las creencias. En el mismo papiro de Oxirrinco 1800, fragmento 1 , se señala que Safo, "es acusada de disoluta o amante de mujeres"17. Esta misma duda se presenta en Dídimo, como también en Séneca, los cuales la consideran como una prostituta ${ }^{18}$. Aún más clarificador sobre la oscuridad en la que se transita cuando uno se sumerge en la figura de la poeta de Éreso, es la propuesta de Ninfodoro, quien planteó la existencia de dos Safo: “la poetisa, nacida en Mitilene, y la hetera, nacida en Éreso" ${ }^{19}$. No menos falso que lo anterior, es el amor entre Safo y Anacreonte señalado por el biógrafo Camaleonte $^{20}$.

En síntesis, Rodríguez Adrados asevera: “del mismo modo que estos temas eróticos en relación con Safo son pura fantasía, igual lo es su supuesto carácter de hetera, de prostituta homosexual como dice Taciano" ${ }^{21}$. Parece primordial, ante la variedad de relatos que se han construido de ella y los continuos juicios de valor, tener el cuidado de evitar la categorización o encasillamiento en base a sistemas de valores que Safo no conoció. Para ello hay que limitarse a la información que se tiene, aun cuando sea fragmentaria.

Lo que sabemos es que nació en la segunda mitad del siglo VII, más precisamente en torno al 630 a. C, en la ciudad de Éreso, ubicada en la parte suroccidental de la isla de Lesbos y que su vida se desarrolló en la ciudad de Mitilene en la misma isla ${ }^{22}$. Debido a la ubicación de esta (isla) en el oriente del mar Egeo, fue un lugar de "una refinada cultura donde a lo griego se une una cierta elegancia oriental y unos prestigios exóticos" ${ }^{23}$. Se dice que estuvo casada con "Cércilas de Andros y tuvo una hija Cleis" ${ }^{24}$. Emilio Suarez de la Torre, relativiza esta información, en especial, la relacionada con su marido, por considerarla una invención de los cómicos áticos, los cuales encontraron en Safo un objeto de burla ${ }^{25}$. Bastante más clara, es la figura de su padre Escamandronio y sus hermanos Lárico, Caraxo y Erigüio ${ }^{26}$.

\footnotetext{
${ }^{16}$ Rodríguez, Francisco. 1980. Lírica griega arcaica, (poemas monódicos y corales 700-300 a. C), Madrid, Gredos, p. 336.

17 Ídem, p. 337

18 Séneca, Epístolas, 88, 37.

${ }^{19}$ Ninfodoro, Ateneo, $596 \mathrm{f}$.

${ }^{20}$ Ateneo, 599 d-e.

${ }^{21}$ Rodríguez, Francisco. 1980. Lírica griega, p. 338.

22 García, Fernando. 2017. De hombres y dioses, p. 169

${ }^{23}$ García, Carlos. 2013. Antología de poesía lírica griega siglo VII-IV, Madrid, Alianza, 2013, p. 93.

${ }^{24}$ Rodríguez, Francisco. 1980. Lírica griega, p. 340.

${ }^{25} \mathrm{El}$ motivo es que Cércilas significa, el que tiene cola de hombre. Suarez, Emilio. 2019. Antología de la lírica griega arcaica, Madrid, Cátedra, p. 151; véase también: García, Fernando. 2017. De hombres y dioses, p. 170.

${ }^{26}$ Rodríguez, Francisco. 1980. Lírica griega, p. 340.
} 
Los testimonios señalan que eran de origen noble, pero se encontraban económicamente arruinados $^{27}$, debiendo ser sustentada económicamente por sus amigas ${ }^{28}$. Era una mujer reconocida al ser educadora de las muchachas más renombradas de la aristocracia de la isla y de Jonia, a ella, llevaban las adolescentes para ser instruidas en las diversas artes, en aquel thíasos $(\theta i a \sigma o \varsigma)^{29}$ característico de Mitilene ${ }^{30}$. En esta zona "la participación de coros de música, canto y danza en festividades civiles y religiosas era tan elevada que fue necesario profesionalizar maestros y directores para coros de muchachos y muchachas de cierta condición social" ${ }^{31}$. Esto da testimonio del grado de refinamiento, pero también del grado de libertad de las mujeres en comparación a lo que vivirían con posteridad en la Atenas el siglo $\mathrm{V}^{32}$.

Con esto, no pretendo contradecir lo que Claude Mosse ${ }^{33}$ y Sarah Pomeroy ${ }^{34}$ señalan sobre la condición de segregación de la mujer a través de toda la historia de la Grecia antigua, pero sí considero, que existen dentro de esa generalidad ciertos matices, los cuales, no podemos considerar como ejemplos de equilibrios plenos entre los géneros, pero sí, de menores diferencias que en otros contextos.

"El círculo de Safo es, en cierto modo, la contrapartida de los clubes aristocráticos de varones, como el de Alceo. Safo se dirige a sus amigas como Alceo a sus amigos" ${ }^{35}$. Los temas manifestados en sus poesías no están vinculados ni a la guerra ni a la política, sino a las fiestas, al erotismo, a su relación con sus amigas, como también autobiográficos, Suarez de la Torre menciona:

\footnotetext{
27 Safo, Fragmento, 98. "No tengo, Cleis, de dónde hacerme para tí con un tocado multicolor..."

${ }^{28}$ Safo, 213a. En este fragmento pone nuevamente el lujo como componente esencial, pero con el tono de quien lo ha perdido, pero que es ayudada a seguir disfrutando de ellos, el papiro de Oxirrinco 2506 lo expone con mayor fuerza. Citado por: Rodríguez, Francisco. 1980. lírica griega, p. 340.

${ }^{29}$ Schadewaldt, considera a este Thíasos. como centros educativos con características iniciáticas, para preparar a las doncellas para el matrimonio, pero claro con un alto grado de desarrollo, propios de la isla de Lesbos. Schadewaldt, Wolfgang. 1973. Safo Mundo y poesía. Existencia en el amor, Buenos Aires, Eudeba. p. 58. En cuanto al tema del Thiasos lésbico y su relación con el erotismo y la sexualidad, recomendamos el excelente trabajo de Vega, Irina. 2016. "Una aproximación al Thíasos lésbico desde la lírica de Safo", en Revista de estudios clásicos, № 43, Cuyo, pp. 233248.

${ }^{30}$ Si bien el Thíasos lésbico, tenía características singulares debido al contexto insular de Lesbos y en particular el Thíasos sáfico por su simpatía con la cultura oriental, cabe destacar que esta era una institución extendida en gran parte de la Grecia arcaica, sino toda. También sería un error creer que la homosexualidad femenina era exclusiva de Lesbos, pues Alcmán nos expone sobre la existencia de esta en Esparta. Al respecto recomendamos el comentario de Gentili, Bruno. 1996. Poesía y Público en la Grecia Antigua, Barcelona, Quederns Crema, pp. 187-193.

${ }^{31}$ Montemayor, Carlos. 1986. Safo, poemas, Ciudad de México, Trillas. p. 22

32 Mosse, Claude. 1991. "Sapho de Lesbos", en Amour et sexualité en occident, Paris, Seuil, pp. 43-51

33 Mosse, Claude. 1990. La mujer en la Grecia clásica, Madrid, Nerea, p. 36.

34 Pomeroy, Sarah. 1999. Diosas, rameras, esposas y esclavas: Mujeres en la antigüedad clásica, Madrid, Akal. Para un tratamiento de este tema recomiendo González, Francisco. 1996. "Mito e ideología: supremacía masculina y sometimiento femenino en el mundo griego antiguo", en Ibid., Bermejo, José; Reboreda, Susana: Los orígenes de la mitología griega, Madrid, Akal, 163-216.

${ }^{35}$ Rodríguez, Francisco. 1980. Lírica griega, p. 342.
} 
"En ese círculo sáfico hay jóvenes que se preparan para su integración, mediante el matrimonio, en el mundo de los adultos, de predominio masculino, a través de la experiencia del grupo, presididas por Afrodita y su mundo, por la poesía, el canto, la danza que no excluía (sino todo lo contrario) el compartir experiencias eróticas de manifestaciones y gradaciones muy diversas" ${ }^{36}$.

El amor a sus amigas es el tema de mayor preponderancia dentro de los fragmentos que nos han llegado, en la cual, la poetisa de Lesbos manifiesta su pesar en algunos casos por perder el amor de estas o por no conseguirlo, pese a sus pedidos a Afrodita. Los celos, la separación y todo lo vinculado al amor y el desamor se manifiesta con fuerza en su trabajo ${ }^{37}$.

Francisco Rodríguez destaca que estas relaciones con las mujeres de Lesbos no eran incompatibles con la vida matrimonial o familiar, la estructura de valores es de un carácter diferente, Safo se manifiesta crítica para con el eros heterosexual, pero lo acepta como algo normal y casi inevitable. "Es un ambiente que, frente a una sociedad fuertemente masculina, con sus organizaciones y sus ideales, surge como contrapartida otra sociedad femenina. Hay entre ambas, por así decirlo, una especie de tregua, de punto de contacto, que es el matrimonio. Pero los verdaderos ideales están fuera de allí" ${ }^{38}$.

Todo lo anterior, envuelto en un ambiente religioso, pues para los griegos todo estaba revestido por los dioses ${ }^{39}$, pero contextualmente en un escenario de profundas transformaciones políticas, conflictos por el poder e inestabilidades que llevaron a la poetisa al exilio en Sicilia entre el 605 - 595 a.C. ${ }^{40}$, contexto, donde muy probablemente le fueron confiscados sus bienes, estando el tirano Mirsilo en el poder ${ }^{41}$.

Cuando Mirsilo fue depuesto y Pítaco tomó el control en Mitilene, pudo volver del exilio, mas, su situación de vida no mejoró mucho, y sus conflictos con este (Pítaco), al cual llama despectivamente el Mitileno, y a su esposa la Pentílida (de la cual no tenemos plena certeza si era Andrómeda o Gorgo), fueron recurrentes. Es más, esta Pentílida era una de las educadoras rivales y con las cuales luchó sistemáticamente por el amor de sus alumnas, testimoniándonos como estas relaciones estaban marcadas por las rivalidades políticas, sociales y culturales ${ }^{42}$.

La poesía de Safo se hace compleja de interpretar, no solo por la cantidad de relatos que de ella se han elaborado, sino también por lo personal de sus temas, lo fragmentario de los textos

\footnotetext{
${ }^{36}$ Suarez, Emilio, 2019. Antología de la lírica griega arcaica, Cátedra, Madrid, p. 152.

37 Safo, 16, 31, 49, 68, 73, 94 y 95, entre otros nos lo testimonian.

38 Rodríguez, Francisco. 1980. Lírica griega, p. 345.

${ }^{39}$ Vernant, Jean Pierre. 1993. El hombre griego, Madrid, Alianza, p.19.

40 Suárez, Emilio, 2019. Antología, p. 151.

${ }^{41}$ Rodríguez, Francisco. 1980. Lírica griega, p. 345.

42 Gentili, Bruno, Poesía, pp. 202-203.
} 
que nos han llegado y el continuo desplazamiento del espacio de los seres humanos al de los dioses, lo cual implica un cuidadoso análisis, pero no por ello, un esfuerzo imposible de realizar.

\section{La figura de Alceo y su contexto}

La vida de Alceo es inseparable de la vida política de su natal Lesbos y los conflictos militares que la envolvieron. De origen aristocrático, tenemos conocimiento de dos hermanos, los cuales eran mayores que él, Antiménidas y Ciquis, y que, al igual que Alceo, participaron en batallas y de la vida pública de su tierra natal. Además de lo anterior, también sabemos de la relación que Alceo tuvo con Safo, según nos lo expresa el fragmento $384^{43}$.

Se opuso, junto con Pítaco (que hasta ese momento aún no era su rival declarado), a la tiranía de Mirsilo. La oposición a la tiranía de este le significó su primer destierro, que finaliza con la muerte del tirano, siendo motivo de especial alegría según lo registra el fragmento 332.

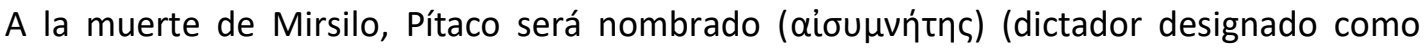
gobernante en tiempos de guerra), debido a sus dotes como estadista y político, puesto que ocuparía por diez años y, al cabo de los cuales, decide dimitir para que se elija a un nuevo gobernante.

Bajo el liderazgo de Pítaco, Mitilene disfrutó de una gran prosperidad e implicó la eliminación de la tiranía, pero a ojos de Alceo, Pítaco era como una especie de extensión de Mirsilo y su gobierno. Los fragmentos 74 y 141 testimonian la oposición que el célebre poeta llevó adelante en contra del aisymnêtēs de Mitilene, lo que le valió partir nuevamente al destierro junto a su partido. Además de esta relación entre Mirsilo y Pítaco, las menciones a este último son continuas y recurrentes como el fragmento 75 , en el cual se burla de su clase social inferior y sobre su matrimonio con una mujer Pentílida: “...que los que yerran soporten un deshonor ya antes anunciado, es fuerza. Lo recuerdo: todavía como un niño... pequeño estaba yo sentado... se... el Pentílida... pero ahora el cambio... un hombre mal nacido... tiranizar..." ${ }^{44}$

En el destierro, participó ayudando a los lidios en el conflicto contra Astiages, con el objeto de ganar el apoyo de estos. Su plan era emprender su campaña contra Pítaco, al cual, intentó derrocar en diversas ocasiones con todo tipo de artimañas, mas, todas ellas finalizaron en rotundos fracasos. Como dice Rodríguez Adrados: "Eterno luchador por el poder en un momento en que la aristocracia tendía a ser desplazada, sustituida por un poder personal que abría la vía del futuro, le tocó perder casi siempre, bajo la sombra de la personalidad poderosa de Pítaco, el tipo mismo del reformado a la manera de Solón..." 45.

\footnotetext{
43 Safo, 384.

${ }^{44}$ Alceo, 75. Sobre Pítaco podemos mencionar también los fragmentos: 76, 113, 114, 141, 167, 169.

${ }^{45}$ Rodríguez, Francisco. 1980. Lírica griega, p. 297.
} 
Por otra parte, Alceo está unido a los antiguos valores de la nobleza, adherido hasta lo sumo a la aristocracia, admirador de la cultura y tradiciones heroicas y adepto a la religión como rectora del destino de las sociedades, "unido sentimentalmente a un pasado ya muerto; su violencia y pasión le hacían perder en el juego de la política" ${ }^{46}$.

Su poesía es directa y expresiva, descubriéndonos el velo del mundo del banquete masculino y las conspiraciones políticas, pero también el del vino, las relaciones eróticas homosexuales y heterosexuales ${ }^{47}$. Destacan en sus escritos las descripciones colmadas de añoranza, pasión, tristeza, muerte y, por debajo de estas, la idea del fracaso siempre latente. Es el cantor del simposio y el éros, un autor de himnos perfectos a los dioses. "Hay que decir que Alceo es el inventor de la composición lírica a saltos a la manera de Píndaro" 48.

En su poesía se vislumbra la influencia de Homero, Hesíodo, Arquíloco y Estesícoro, de este último hará eco de las advertencias contra el tirano. Sus himnos son de carácter tradicionalista y de estructura ternaria, tendrán en el mito su instrumento para transmitir el mensaje, haciendo uso de este para atacar a sus enemigos. Su obra transita desde el mito a la vida personal, "el mito se entremezcla con las máximas, a la manera de toda la antigua poesía" 49 .

La obra de Alceo es difícil de clasificar, debido al desplazamiento entre el mito y la vida cotidiana, donde como hemos mencionado, la política, el componente erótico y el simposio se presentan como el leitmotiv de su cantar, cantar que tenía el objetivo de ser presentado en los banquetes y fiestas de su círculo de amistades.

La poesía de Alceo es, de esta manera, una herramienta de inmenso valor histórico que refleja, pese a lo fragmentario de los escritos que nos han llegado, las trasformaciones políticas, sociales y culturales de su natal y amada Mitilene. A esto se agrega que la mayor parte de los versos que hoy poseemos fueron recién recuperados a inicios del siglo XX, lo que lo transforma en una fuente que aún no consta con toda una tradición histórica en su estudio. Fragmentos dispuestos para ser explorados y analizados para, a través de su mágica pluma, conocer las emociones y sentimientos que permeaban, en el final del siglo VII e inicios del VI a. C. a la isla de Lesbos.

\section{Una mirada general a la semántica del amor en la poesía lésbica}

En un artículo anterior titulado "Un acercamiento al lenguaje del amor en las obras de Homero y Hesíodo" 50 , puse especial énfasis en el campo semántico de los conceptos que regularmente se han traducido por "amor". Como dice Rodríguez Adrados: "sin entender las palabras en que

\footnotetext{
46 Ídem.

47 García, Fernando. 2017. De hombres y dioses. p. 189.

${ }^{48}$ Rodríguez, Francisco. 1980. Lírica griega, p. 298.

49 Ídem, p. 299.

50 Saavedra, Alejandro. 2020. “Un acercamiento al lenguaje del amor en las obras de Homero y Hesíodo", en Historias del orbis terrarum, №24, Santiago, pp. 8-31.
} 
se expresa una cultura, es imposible penetrar en ella salvo con groseras simplificaciones" ${ }^{21}$. Cabe señalar, que hablar de la semántica del amor en la poesía lésbica, es hablar de Safo, lo que implica dejar de lado por un momento a Alceo, debido a que los fragmentos con los cuales contamos están centrados en las rivalidades política y el banquete en el simposio. Los alcances a aspectos afectivos y en particular al "amor" son escasos al no ser esta su principal temática poética, motivo por el que volveremos sobre él más adelante.

Este reducido y general repaso del lenguaje del amor en Safo, es en gran parte tributario del ya clásico trabajo de Francisco Rodríguez Adrados: "Sociedad, amor y poesía en la Grecia antigua", recordando que no hay ningún concepto plenamente congruente con los nuestros.

Como sabemos el lenguaje del amor se divide en dos grandes grupos: el erótico o del deseo y el de la amistad y/o cariño, los cuales, pese a sus contraposiciones, tienden a no ser tan fijos y en muchos casos a traslaparse ${ }^{52}$. Considerando esto, comenzaremos repasando el primero de estos (el lenguaje erótico), para luego dedicarnos al lenguaje de la amistad.

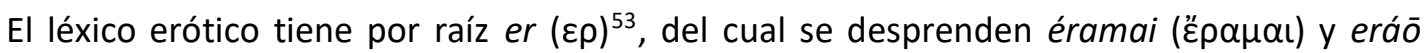
(દ̀pó $\omega$ ), que en términos generales significan desear o estar deseoso de, teniendo un carácter

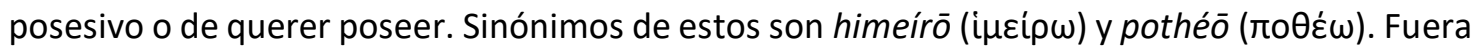
de estos también se presentan aquellos que tienden a tener un sentido más amplio, pero que de igual modo son utilizados para referirse al deseo o la añoranza de algo o alguien, tales como:

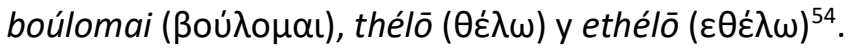

Es interesante la diversidad de formas de uso de los términos en Safo, que dan cuenta de la

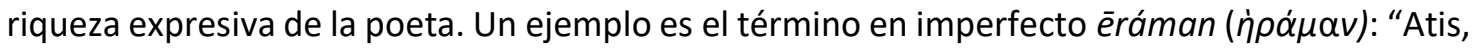
me he enamorado de ti hace ya mucho tiempo" ${ }^{\prime 55}$. El término que de base hace referencia al deseo, nos pone en el umbral del aprecio, de la añoranza, cargando de emotividad la escena y, con ello, dando una muestra más de lo flexible del lenguaje erótico que se mueve en la

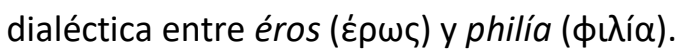

Por otra parte, también el término se visualiza sublimado al campo de la divinidad como en el fragmento 47, donde Eros se presenta como un dios poderoso, que somete al deseo a quien golpea "...y Eros sacudió mis sentidos como el viento que en los montes se abate sobre las encinas." ${ }^{56}$, idea que reaparece en el fragmento 130. "De nuevo Eros que desata los miembros

\footnotetext{
${ }^{51}$ Rodríguez, Francisco. 1996. Sociedad Amor y Poesía en la Grecia antigua, Madrid, Alianza, p. 19.

52 Saavedra, Alejandro. 2020. "Un acercamiento", 8-31.

53 Véase, Rodríguez, Francisco. 1995. Estudios de semántica y sintaxis, Barcelona, Planeta, pp. 247-262, Cfr. Rodríguez, Francisco. 1996. Sociedad, pp. 23-35.

54 Ídem, p. 23

${ }^{55}$ Safo, 49.

56 Safo, 47.
} 
me hace estremecerme, esa pequeña bestia dulce y amarga, contra la que no hay quien se defienda" ${ }^{57}$.

Sabido es que existe un doble éros en el ambiente sáfico, "el éros vertido en el rostro de la muchacha que despierta el amor, el dios Eros que sacudió la mente de la poetisa como el viento las encinas" 58 .

Ese amor que se despierta por el rostro bello de la amada se testimoniado en el fragmento 16:

"Ya dicen que la tropa montada en carros, ya la de los infantes, ya la de los navíos, sobre la tierra negra es lo más bello; pero yo, que es aquello que uno ama.

Muy fácil es hacer que cualquier hombre entienda esto: Helena, la que tanto aventajaba a todos en belleza, a su marido, ese hombre noble, lo abandonó y marchose a Troya en un navío y en nada de su hija ni de sus padres muy queridos se acordó ya, sino que la sedujo (la Chipriota) ...

...inflexible (?)... fácilmente... ahora me ha hecho acordarme de Anactoria ausente.

De ella quisiera el andar seductor y el claro brillo de los ojos ver antes que los carros de los lidios y los infantes con sus armas"59

Frente al pasaje antes planteado, Calame, destaca que el término éros se presenta en genitivo, de base eran, lo que representa un estado de pasividad, frente a ese deseo que lo embarga, se transforma en un "sujeto que desea" o "sujeto sexual" al entrar en presencia con el objeto del deseo amoroso ${ }^{60}$, aquel bello rostro que se hace irresistible pone en situación de dominio mediante el eros genitivo (eran) a quien observa ese rostro ${ }^{61}$.

Continuando el recorrido por el lenguaje erótico, nos encontramos con el ya mencionado pothéō, que en Safo se nos presenta como póthos (róӨos), equivalente al deseo propiamente, muchas veces incontrolado como nos lo refleja el fragmento, 48: “...llegaste... hiciste: yo te estaba buscando, has refrescado mis sentidos que ardían de añoranza" ${ }^{62}$. Concepto que se repite en 102, "Dulce madre, no puedo trabajar en el telar: me derrota el amor por un

\footnotetext{
57 Safo, 130.

58 Rodríguez, Francisco. 1996. Sociedad, p. 23.

59 Safo, 16.

${ }^{60}$ Calame, Claude. 2002. Eros, pp. 26.

61 Para el comentario se prefirió la traducción de Fernando García Romero quien traduce el fragmento 16. 18 cómo: "luminoso brillo de su rostro" García, Fernando. 2017. De hombres, a diferencia de la traducción de Francisco Rodríguez Adrados: "Claro brillo de los ojos". En cuanto a la teoría de la visión recomendamos revisar la ya clásica explicación de Platón y sus efectos eróticos presentes en el Banquete 210a y siguientes y en el Fedro 245c y siguientes. Para un tratamiento sobre este tema, vid. Etiam. Vernant, Jean Pierre. 2001. El individuo la muerte y el amor en la antigua Grecia, Barcelona, Paidós, pp. 155-157.

62 Safo, 48.
} 
muchacho por obra de Afrodita floreciente" ${ }^{63}$. Nuevamente se brinda la idea general de que el dios o diosa, en este caso Afrodita, domina y derrota al "sujeto de deseo"64. Frente a esto, cabe

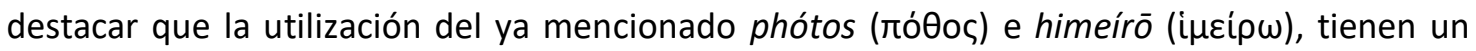
carácter posesivo y pese a que regularmente hace referencia del deseo apasionado que puede ser fuera del campo erótico, en el fragmento 1. 27 Afrodita promete a Safo el cumplir todo lo que su alma desee ${ }^{65}$ con un claro tinte sexual. Calame, manifiesta que póthos e hímeros parecen expresar un deseo más opresivo y cercano a la materialización ${ }^{66}$, que el estado mayoritariamente pulsional de éros.

En el plano de las divinidades también tiene su congruencia, pues Eros no es necesariamente la consumación del deseo, sino un estado descontrolado de anhelo de este. Sin embargo, el efecto de Afrodita comporta regularmente la materialización, lo que la hace más controlado al ser saciado ${ }^{67}$.

Diremos finalmente que en el lenguaje erótico sáfico se manifiesta una amplitud conceptual, pero ciertamente póthos e hímeros no se presentan en una condición de personificación divina (como sí ocurre en la obra hesíodica). De todas formas, en la poesía erótica en general el deseo amoroso depende en última instancia de la Cítera diosa y los artilugios que esta aplique para lograr el cometido del "amor". La misma Safo concibe que el amor es una obra de la diosa o alguna cualidad del ser amado ${ }^{68}$.

Por otra parte, aunque no tan distanciado en la práctica, encontramos el léxico del querer,

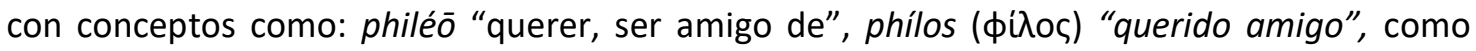
también philótēs y philía "amor, amistad" 69 . Rodríguez Adrados menciona que "el amor de philía se concibe muchas veces como una secuela derivada de éros" ${ }^{\prime 70}$. Es decir, que una relación puede comenzar con el deseo erótico, para luego estimular el desarrollo del afecto, como también los términos pueden alcanzar un cierto grado de equivalencia, como es el caso de la poesía sáfica donde la contraposición de los conceptos es apenas perceptible, tendiendo a presentarse en clave erótica, como en el conocido fragmento 1. 17-34: “...y que es lo que en mi loco corazón más quiero que me ocurra: ¿A quién muevo esta vez a sujetarse a tu cariño? Safo,

\footnotetext{
63 Safo, 102, véase también, 48.2

${ }^{64}$ Calame, Claude. 2002. Eros, p. 26.

${ }^{65}$ Safo, 1. 27.

${ }^{66}$ Calame, Claude. 2002. Eros, p. 36.

${ }^{67}$ García, Carlos. Noviembre de 2010. El amor en Grecia; el poderoso Eros y la gozosa Afrodita, en Congreso General de Grecia, Llevado a cabo en Madrid, p. 3, disponible en http://antiqua.gipuzkoakultura.net/erosAfrodita.php (Consultado el 04 de abril de 2021).

68 Rodríguez, Francisco. 1980. Lírica griega, p. 346.

${ }^{69}$ Rodríguez, Francisco. 1996. Sociedad, p. 29.

70 Ídem, p. 30.
} 
¿quién es la que te agravia? Si ha huido de ti, pronto vendrá a buscarte; si no acepta regalos, los dará; si no te ama, bien pronto te amará, aunque no lo quiera"71.

Lo que la diosa le ofrece a Safo, ante la petición de que la muchacha se pueda enamorar de ella, es un amor de cariño por parte de esta, en respuesta al amor erótico que la poetisa siente $^{72}$. Según Calame, se puede apreciar en son del concepto philei y philótēs, lo cual conlleva una obligatoriedad, un sometimiento a la fidelidad que la joven debe tener, aspecto sobre el cual volveremos más adelante.

El uso conceptual, pese a su alto grado de expresión emotiva y afectiva gira en son del dominio, de la imposición y la búsqueda desenfrenada por la satisfacción del deseo pretendido, impulsado por la belleza de quien es objeto de esta admiración, esto en congruencia con lo que Foucault planteó sobre el uso de los placeres en su Historia de la sexualidad ${ }^{73}$.

\section{Un aterrizaje contextual}

Desde mi punto de vista existe un factor que ha sido retirado del espacio de análisis, debido a que los enfoques interpretativos se han visto dominados por el prisma semántico. Me refiero a la influencia de los ideales y en particular el componente agonístico que permea la mentalidad griega y que es el factor articulador de su $\operatorname{actuar}^{74}$. Vernant señala:

"Es una sociedad competitiva donde para ser reconocido hay que prevalecer sobre los rivales en una competición incesante por la gloria, cada uno se halla expuesto a la mirada del otro cada uno existe en función de esta mirada. En realidad, uno es lo que los demás ven. La identidad de uno coincide con su valoración social: desde la burla al aplauso, desde el desprecio a la admiración" 75 .

Si bien es cierto, con Hesíodo emerge una nueva areté (ảpetń) que pone sus ojos ya no en la competencia y la lucha, sino en la sofhrosyne ( $\sigma \omega \phi \rho o \sigma u ́ v \eta)$, el equilibrio, el autocontrol, la

\footnotetext{
${ }^{71}$ Safo, I, 17-24, Nótese la traducción de Fernando García Romero: “...Y que es lo que más quería que me sucediera en mi enloquecido corazón. ¿A quién otra vez debo obedecerte en llevar a tu amor? ¿quién a ti, Safo, te está agraviando. Porque si te esquiva, pronto te perseguiría y si no acepta regalos, al contrario, los dará, y si no te ama, pronto te amará, aunque ella no quiera.

72 Rodríguez, Francisco. 1996. Sociedad, p. 30.

${ }^{73}$ Foucault, Michelle. 2003. Historia de la sexualidad vol. 2, Buenos Aires, Siglo XXI. Sobre el tema de la belleza como motor sexual Vid. Windschuttle, Keith. 1997. "The myths of Eros", reseña a "Eros: the myth of ancient greek sexuality" de Thornton Bruce, en Partisan Review, Fall, №4, Londres, pp. 656-665. Culturalmente para el griego el principio de dominación se vinculaba a todo aquel que penetra en la relación, no importando si este era hombre o mujer. Vid. Cantarella, Eva. 2004. "L'hermaphrodite et la bisexualité à l'épreuve du droit dans l'Antiquité", dans Diogène, № 208, Paris, pp. 3-15.

${ }^{74}$ Espejo, Carlos. 1994. "Religión e ideología en Homero", en Stvdia Histórica - Historia Antigua, Universidad de Salamanca, N¹2, Salamanca, pp. 9-20.

${ }^{75}$ Vernant, Jean Pierre. 1993. El Hombre Griego, Madrid, Alianza, Madrid, p. 28.
} 
disciplina y el trabajo ${ }^{76}$. Este proceso debe ser matizado, pues, esto está fuertemente marcado por la "imagen del bien limitado", lo que estimula las relaciones de reciprocidad", impactando fuertemente el desarrollo afectivo en la relación ${ }^{78}$. Más allá de esto, cabe destacar que tanto Alceo como Safo, no están bajo ningún aspecto cercanos a la vida aldeana, es más, la misma Safo, como mencioné con antelación, pese a haber quedado económicamente arruinada, era mantenida por sus amigas ${ }^{79}$ y reconocía abiertamente su gusto por los lujos y la utilización de estos en el medio en que se desenvolvía: "pues muchas coronas de violetas y de rosas... también... junto a mi te ponías y muchas guirnaldas trenzadas en torno a tu cuello delicado, hechas de flores... con ungüento de brento... te frotabas y con ungüento real y sobre un blando lecho, la delicada... dabas salida a tu deseo." 80

La vida de Mitilene estaba colmada de los placeres, las excentricidades orientales y los simposios, que se cubrían de manjares, bebidas y utensilios decorados bellamente. Basta con revisar las innumerables referencias que nos deja Alceo al respecto: "Bebamos ¿por qué esperamos a las luces? Queda un dedo de día. Levanta en alto, amigo, grandes copas decoradas, que el vino nos lo ha dado a los hombres, como olvido de los males, el hijo de Sémele y de Zeus. Mezclando una y dos partes, vierte en las copas el vino desde tu cabeza hasta llenarlas y que una copa empuje a la otra" 81

En síntesis, el amor en su continua referencia a la derrota, e incluso esa mirada del dios Eros que domina y envuelve en un deseo ardiente que se traspasa a quien es objeto del deseo, es parte de la concepción agonística (competitiva) de la mentalidad griega, donde las ideas de dominación, afrenta y lucha se hacen recurrentes.

Así como Alceo lucha por el poder en Mitilene, siempre derrotado, así observa el amor como algo peligroso que vence, no por nada le dedica a Eros un himno señalando “...al más poderoso

\footnotetext{
76 Jaeger, Werner. 1962. Paideia: Los ideales de la cultura griega, Ciudad de México, Fondo de cultura económica, p. 78.

77 Gallego, Julián. 2012. “La formación de la polis en Grecia Antigua: Autonomía del Campesinado, subordinación de las aldeas", en Trabajos y Comunicaciones, $N^{\circ} 38$, Buenos Aires, pp. 133-151. Cabe señalar que este factor es el componente que identifica al habitante aldeano. Vid. Foster, George. 1965. "Peasant society and the image of limited good", in American Anthropologist, N 67, Calirfornia, pp. 293-315. Cfr. Francis, Emerich. 1945. "The personality Type of Peasant according to Hesiod's Works and Days", in Rural Sociology, vol.10, №3, New Orleans, pp. 275-295.

${ }^{78}$ Es valiosos considerar, que esta se ve influenciada por la necesidad de tener bendiciones de la tierra, estimulando la contención de las emociones y los deseos por causa de las limitaciones económicas. Véase: Saavedra, Alejandro. 2018. "El ideal de amor conyugal en la época arcaica, a través de las obras de Homero y Hesíodo. Universidad de Concepción, Tesis para obtener el grado de Magister en Historia, pp. 192-197.

${ }^{79}$ Safo, 98

80 Safo, 64, 12-23. Véase también 213a. Gentili, expone el aprecio que la poetisa tenía para con la cultura Lidia, catalogándola de filolidia, rindiéndole un culto a la elegancia. Gentili, Bruno, Poesía, pp. 203-204, situación similar se observa en Alceo el cual según el fragmento 69, recibió ayuda de estos para volver a Mitilene. Observándose una mirada opuesta entre nuestros poetas y el líder político de Mitilene, aumentando las tensiones entre estos.

${ }^{81}$ Alceo, 346. Véase también 347, 1; 368, 2.
} 
de los dioses"82. En la misma línea, Safo menciona en un pasaje ya citado “...esa pequeña bestia dulce y amarga, contra la que no hay quien se defienda" ${ }^{83}$, e incluso la misma poetisa de Lesbos,

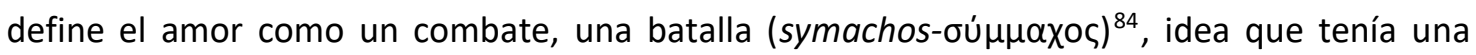
extendida influencia en la poesía arcaica, existiendo una relación continua entre combate y amor en los escritos de los poetas líricos, como observó con profunda agudeza Giuliana Lanata ${ }^{85}$.

A Alceo, su derrota política y sus destierros lo persiguieron continuamente, como mencionamos en el apartado dedicado a su biografía, haciendo continuas reiteraciones a la figura de Pítaco, imagen de la injusticia a sus ojos. El poeta lesbio sufría profundamente el gobierno de este, no solo por el exilio que le significó, sino por verse siempre desplazado por las habilidades del aisymnêtēes (aiounvńtns) de Mitilene, viendo herido su orgullo aristocrático,

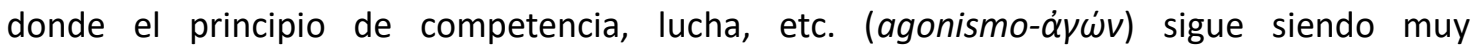
preponderante. Alceo pareciera que reitera tanto su situación de derrota que pretende exorcizar su presente mediante ello, como buscando escapar de su realidad ${ }^{86}$.

Por otra parte, a Safo no solo le duele que la dejen, sino que la dejen por alguna de sus rivales, ya sea Andrómeda ${ }^{87}$ o Gorgo ${ }^{88}$. Por ende, no es raro que destaque a la primera en reiteradas ocasiones y siempre aseverando la condición de rivalidad frente a esta: “...pues que yo de la... pero sin embargo sucedió... ella semejante a los dioses... la culpable... Andrómeda... feliz... el modo... no refreno la hartura... Tindárida... bello... sin engaño... ya no... Megara". ${ }^{89}$

Bruno Gentili, llamo a esto el "agon amoroso"90, en momentos tocaba ganar como al parecer lo revela el mordaz fragmento 133: "Tiene Andrómeda la respuesta que merece" ${ }^{91}$, como también perder, como en el fragmento 71-73, donde una joven llamada Mica se marcha con la

\footnotetext{
82 Alceo, 327.

83 Safo, 130.

${ }^{84}$ Safo, 1.28 "Sé mi aliada en la batalla", Como señala Cerezo, siempre es mejor que la diosa luche a su lado que tenerla en contra. Cerezo, Manuel. 1987. "El mundo del amor y Safo", en Scriptura, N³, Lérida, p. 12.

85 Lanata, Giuliana. 1966. "Sul linguaggio amoroso di Saffo", Quaderni Urbinati di Cultura Classica, № 2, Pisa-Roma, pp. 63-79. Cfr. Gentili, Bruno. Poesía, pp. 195-196.

86 Una interpretación similar, pero a la luz de la poesía de Juvenal sobre la pobreza Cubillos, Marcela. 1999. "Historia social del mundo clásico: terminología de la pobreza en Roma a partir de Juvenal (I y II d.C.)”, en Archivum, $N^{\circ} 1$, Viña del Mar, pp. 89-94.

${ }^{87}$ Al parecer la mayoría de los casos son por causa de esta. Vid. $65 ; 68 ; 73 ; 130$.

88 Safo, 103 c

89 Safo, 68 a. Es tanto el dolor o la rabia que le provoca que Megara se marchase con Andrómeda, que llama a la muchacha Tindarida, es decir, la iguala a Helena y en especial a Clitemnestra, las hijas de Tíndaro, con todo el peso de ser llamada de esa forma, equivalente a una traidora y asesina. (sabemos que Zeus engendró a Helena, al convertirse en cisne y copulando con la esposa de Tíndaro).

90 Gentili, Bruno. 1996. Poesía, p. 205.

${ }^{91}$ Véase el comentario de Gentili al respecto en Ídem.
} 
Pentílida ${ }^{92}$. De esta manera, el amor se presenta en una doble dimensión, que se le anhela, pero causa dolor para quien no lo obtiene o lo pierde, dolor tanto por la pérdida, como por la derrota:

"Me parece igual a los dioses aquel varón que está sentado frente a ti y a tu lado te escucha mientras le hablas dulcemente y mientras ríes con amor. Ello en verdad ha hecho desmayarse a mi corazón dentro del pecho: pues si te miro un punto, mi voz no me obedece, mi lengua queda rota, un suave fuego corre bajo...brota de mí el sudor, un temblor se apodera de mi toda, pálida cual la hierba me quedo y a punto de morir me veo a mí misma. Pero hay que sufrir todas las cosas...mi piel, nada veo con mis ojos, me zumban los oídos." ${ }^{93}$

Estas relaciones son eminentemente pederastas ${ }^{94}$, siendo de carácter asimétrico, donde el "adulto domado por Eros se transformaba en domador del adolescente que la inspira" ${ }^{95}$. El mismo Calame, asevera que el concepto que se utiliza para mencionar esta relación asimétrica

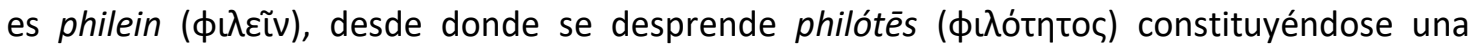
paidophileín ( $\pi \alpha\llcorner\delta \circ \phi \iota \lambda \varepsilon \bar{v})$, entronizando una dominación sobre el sujeto de deseo que son los adolescentes y, en el caso de Safo, las señoritas educadas por ella ${ }^{96}$.

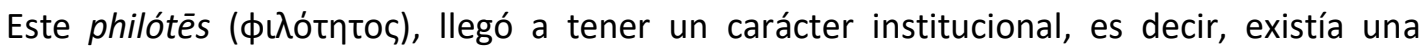

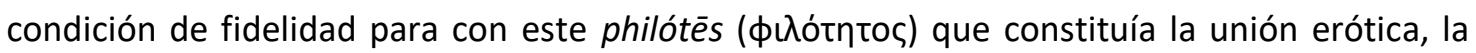
ruptura de esta relación formada entre la maestra y las alumnas era considerada como un acto de injusticia, pues tenía un carácter sagrado ${ }^{97}$. La alumna amada que no correspondía no solo causaba un agravio a su maestra, en este caso a Safo, sino también a la diosa Afrodita, ya que quebrantaba una norma constituida por el principio de reciprocidad, norma que estaba desligada del factor de voluntad del amado o amada ${ }^{98}$. En cuanto a la reparación del acto de injusticia, este no tendrá lugar hasta que la muchacha sea una adulta y "el equilibrio requerido por la dike (ઠíkn) solo se conseguirá cuando la joven amada alcance la plenitud del amor adulto" 99 .

Es interesante que las relaciones homoeróticas, en este caso femeninas, se manifiestan en un estado asimétrico, en son de la posición de subyugación de la adolescente frente a su

\footnotetext{
92 “...no es justo (?) que tú, Mica, pero yo no voy a dejarte... preferiste el amor de las Pentílidas". Safo, 71-73. En cuanto a la identidad de la llamada Pentílida Schadewaldt se inclinará por Andrómeda, vid. Schadewaldt, Wolfgang. 1936. "Zu Sappho", en Hermes vol.71, N 3, Alemania, pp. 363-373. Mientras que Treu lo hará por Gorgo, Treu, Max. 1976. Sapho et. al. (edición griega), München, 1976, p. 146, n 2. Citado por: Gentili, Bruno. 1996. Poesía, p. 202.

93 Safo, 31.

${ }^{94}$ Claude Mossé. 1991. Sapho, pp. 43-51.

${ }^{95}$ Calame, Claude. Eros, p. 32.

96 Ídem.

97 Ídem, p. 31.

98 Gentili, Bruno. 1996. Poesía, p. 205.

${ }^{99}$ Calame, Claude. Eros, p. 31.
} 
maestra, pero también en las posibilidades múltiples de construcción de las relaciones que tenían las educadoras. El fragmento 213, 4 nos presenta el caso de Pleistódice y Gongila las cuales eran esposas Gorgo (una de las grandes rivales de Safo), testimoniando la posibilidad que tenían las directoras del thíasios de formar parejas con más de una joven al mismo tiempo ${ }^{100}$.

Cabe destacar que, en la condición de simetría no se observan relaciones formadas, pues las jóvenes que dejan a Safo, ya sea para marcharse con su rival, o más comúnmente para el matrimonio, no retornarán para constituir una relación en cierto grado simétrica estando ambas en la madurez, quedando esta relación ("la relación simétrica") circunscrita a su relación conyugal. Esto podría mirarse a la luz de la relación en torno al lecho matrimonial donde se genera la procreación ${ }^{101}$, pero eso sin lugar a duda escapa a los alcances de los poetas lesbios, pues no es un tema visible en ellos, superando los límites de este trabajo.

El hecho de que la simetría no se vea expuesta en la poesía, pero sí su contrapartida, la asimetría, es probablemente el resultado de los deseos escondidos, en los cuales la caída bajo el dominio de éros, es el medio para legitimar su posterior actitud dominante y agresiva y la ausencia de la relación simétrica. Esto revela el desinterés que esta les generaba, siendo indigna de mencionar, e incluso cuando Alceo pudo constituirla al retornar la mujer que lo había rechazado en la juventud, este la rechaza también:

"Quien, desgraciada... decir... te ofreció... Ilama al dios no culpable pues que nada te falta: pues yo (?) tu insensatez... pero a mi déjame y en (tantos) males si puedes retener...Porque tu tiempo ya ha pasado y el fruto que había ha sido todo recogido. Había esperanza de que tus sarmientos - son bellos en verdad - dieran racimos nada escasos, pero es tarde (?), de una vid como esa... buscando... temo que los vendimien verdes y ácidos. ...los que en un tiempo trabajaron... jamás... fuerte... procura..." ${ }^{102}$.

Esta metáfora agraria nos revela que las relaciones medianamente simétricas se materializan en la adultez, pero no tienen la importancia para ser concretadas en la experiencia de los poetas mismos y solo se casan en los poemas las jóvenes traidoras que abandonan a Safo. Es más, la poetisa en una de sus referencias a amores heterosexuales señala que la mujer espera a su marido, pero este nunca llega para materializar el vínculo sexual: "Se ha puesto la luna y las Pléyades: es la media noche: pasa el momento, y yo duermo sola" ${ }^{103}$.

Es interesante que Rodríguez Adrados señala que en Homero no se observa homosexualidad debido, en parte, a las menores distancias sociales entre el varón y la mujer, lo cual, la hacían

\footnotetext{
100 Safo, 213, 4. Vid. Gentili, Bruno, Poesía, pp. 194-195.

101 Ídem, p. 39.

102 Alceo, 119.

${ }^{103}$ Safo, 168 b
} 
un ser aún "valioso"104. Pero en el plano de la poesía lírica, las relaciones homoeróticas eran primordialmente de carácter pederasta, en un contexto de asimetría, es decir, también en un tejido sociocultural de diferencia jerárquica.

Para ir cerrando, es necesario precisar que, pese a todas las imágenes referidas a relaciones homoeróticas, tanto masculinas como femeninas, estas no gozaron de una aceptación plena, como uno pudiese imaginar en la sociedad griega en general ${ }^{105}$. En la Lesbos del siglo VII y VI a. C., existían aún amplios márgenes de acción, debido a que no era una sociedad cubierta por un conjunto de normas, donde los componentes religiosos de carácter relativamente privado tenían una inmensa importancia. Sumado a esto, los simposios eran conformados por círculos reducidos y no como actos públicos de gran población. Safo misma, pese a no ser sacerdotisa de Afrodita ${ }^{106}$, revestía sus encuentros de la estela de la diosa del amor. Al igual que como se observa en Alceo en el fragmento 296, esto permitía practicarlos de manera más tranquila, bajo el cobijo de la religión, en medio de los ritos iniciáticos del thíasos y el simposio ${ }^{107}$.

\section{Conclusiones}

El amor a la luz de la poesía lésbica tiende a tomar un tenor de dominación, pues la relación simétrica no se constituía y quedaba supeditada a un plano puramente espiritual, donde la diosa hará retornar el amor, como lo prometido a Safo, pero cuando está realmente retornado no se materializaba, como el caso del rechazo de Alceo, o no se concretaba, como la esposa que está en vela esperando a su marido. Como consecuencia de esto, el amor es un continuo estado de sufrimiento, un estado pulsional de anhelos que en ciertos momentos se materializan, y cuando se materializan, están destinados a finalizar.

El amor se aprecia congruente con el contexto de transformaciones, es decir, en una continua inestabilidad y estado de conflicto, que se manifiesta en son con el ideal del agonismo, pues las derrotas en la lucha que hieren el honor del noble son también en la mujer, la derrota y la afrenta por el amor perdido. Se compite en todo, ya sea para ser el líder político, o para ser la mejor educadora, en fin, el principio de competencia articula la forma como se concibe el afecto.

Como consecuencia de lo anterior, el espacio de los dioses, pese a ser mucho más cercano a las experiencias efectivas de los mortales, a diferencia de Hesíodo (que se observa una

\footnotetext{
104 Francisco, Rodríguez. 1981. El mundo de la lírica griega antigua, Madrid, Alianza, pp. 41-46.

105 Devereux, Georges. 1979. "La pseudo homosexualité grecque et le miracle grec", Ethnopsychiatrica, Vol. II, №2, Grenoble, pp. 211-241.

${ }^{106}$ Basta solo con pensar en lo recurrente que eran las apariciones de la diosa del amor, la cual, consolaba, dialogaba y acompañaba a la poetisa en sus incursiones amorosas y sus momentos de pesar. En cuanto a las epifanías y las apariciones oníricas en la antigüedad griega recomendamos el trabajo de Dondds, Eric. 1997. Los griegos y lo irracional, Madrid, Alianza.

107 Gentili, Bruno. 1996. Poesía, pp. 193-195.
} 
contraposición total entre los mortales y los dioses y las relaciones que constituyen) ${ }^{108}$, terminan siendo los receptores de los anhelos de los poetas, pudiendo constituir relaciones y materializarlas donde los humanos no pueden ${ }^{109}$. Como consecuencia de esta incapacidad, a Eros se le teme y, con ello, también se le teme al amor. Esto puede ser una forma elevada y más controlada de transmitir una idea que posteriormente será mucho más clara y radical, y es la concepción negativa del amor, asimilado como una locura peligrosa, pero que en este contexto aún no llega a ese punto.

En suma, los deseos sexuales se ven sublimados, pues el amor pederasta que se busca alcanzar, se ve validado, o por lo menos se intenta, pues la afrodita de la épica insufladora del amor heterosexual (como dice Rodríguez, no hay homosexualidad en las obras homéricas) es ahora la dadora, la insufladora del amor homosexual, que encuentra en la diosa su origen, fuerza y capacidad de permanencia, haciendo de este un deseo no negado sino permitido o, por lo menos si se quiere, medianamente permitido dentro de cierto contexto.

Sucintamente diremos que este amor propio de Lesbos se articula como el resultado del deseo de dominio, y ante el cual, la mujer aún no ha sido sometida, pero que nos testimonian que implícitamente el deseo de dominación se aprecia de forma subrepticia en el ataque de Eros, haciendo a los mortales un "sujeto de deseo", obligando al mortal a someter a otro.

Esta forma de expresión agresiva y dominante del amor ve su justificación, pues es el dios el que impone la dominación, aun cuando esta se materializa sólo en el campo de la pederastia, pero cimentando las bases de una posible dominación en las relaciones de todo tipo en el futuro.

\section{Referencias citadas}

\section{Fuentes:}

Alceo. 1980. Fragmentos. Traducción de Francisco Rodríguez Adrados, Madrid, Gredos.

Bonifas Nuño, Rubén (Trad.). 1988. Antología de la lírica griega (edición bilingüe), México, UNAM. García Gual, Carlos (Trad.). 2013. Antología de la poesía lírica griega (siglos VII-IV a.C.), Madrid, Alianza.

Suárez de la Torre, Emilio (Trad.). 2019. Antología de la lírica griega arcaica, Madrid, Cátedra. García Romero, Fernando (Trad.). 2017. De hombres y dioses. Antología de poesía lírica griega antigua (siglo VII-V), Edición bilingüe, Salamanca, Escolar y Mayo editores.

Safo. 1980. Fragmentos. Traducción de Francisco Rodríguez Adrados, Madrid, Gredos.

Safo. 1986. Poemas. Traducción de Carlos Montemayor, Ciudad de México, Trillas.

\footnotetext{
108 Saavedra, Alejandro. 2018. El ideal, pp. 186-187.

${ }^{109}$ Alceo, 308, Zeus se une a Maya engendrado las cimas.
} 


\section{Bibliografía:}

Alsina, José. 1983. Literatura Griega, Barcelona, Ariel.

Calame, Claud. 2002. Eros en la antigua Grecia, Madrid, Akal.

Camps, Victoria. 2011. El gobierno de las emociones, Barcelona, Herder.

Cantarella, Eva. 2004. "L'hermaphrodite et la bisexualité à l'épreuve du droit dans l'Antiquité", en Diogène, № 208, Paris, pp. 3-15.

Cerezo, Manuel. 1987. “El mundo del amor y Safo”, en Scriptura, №3, Lérida, pp. 5-13.

Elsner, Paulina, Montero, María, Reyes, Carmen y Zegers, Beatriz. 1993. La familia una aventura, Santiago, Universidad Católica de Chile.

Espejo, Carlos. 1994. “Religión e ideología en Homero”, en Stvdia Histórica-Historia Antigua, № 12, Universidad de Salamanca, Salamanca, pp. 9-20.

Foucault, Michelle. 2003. Historia de la sexualidad, vol. 2, Buenos Aires, Siglo XXI.

Francis, Emerich. 1945. "The personality Type of Peasant according to Hesiod's Works and Days", en Rural Sociology, N 10, Nueva York, pp. 275-295.

Frevert, Ute. 2011. Emotions in History: Lost and Found, Budapest, Central European University Press.

Gadamer, Hans. 1993. Verdad y Método, Salamanca, Sígueme.

Gallego, Julían. 2012. "La formación de la polis en Grecia Antigua: Autonomía del Campesinado, subordinación de las aldeas", en Trabajos y Comunicaciones, №38, Buenos Aires, pp. 133-151.

García, Carlos. 2010. El amor en Grecia; el poderoso Eros y la gozosa Afrodita, en Congreso General de Grecia, llevado a cabo en Madrid, p. 3. Disponible en http://antiqua.gipuzkoakultura.net/erosAfrodita.php (Consultado el 04 de abril de 2021).

Gentili, Bruno. 1996. Poesía y Público en la Grecia Antigua, Barcelona, Quederns Crema.

George Foster, George. 1965. "Peasant society and the image of limited good", en American Anthropologist, N67, California, pp. 293-315.

Devereux, Georges. 1979. "La pseudo homosexualité grecque et le miracle grec", Ethnopsychiatrica, Vol. II, N², Grenoble, pp. 211-241.

Grondin, Jean. 1999. Introducción a la hermenéutica filosófica, Barcelona, Herder.

Jaeger, Werner. 1962. Paideia: Los ideales de la cultura griega, Ciudad de México, Fondo de cultura económica.

De Toro, José. 2016. "Apud indos ver perpetum. El extremo oriente durante la Edad Media: una revisión del horizonte onírico de Jacques Le Goff", en Revista de Historia, vol. 1, N²3, Concepción, pp. 73-99.

Dondds, Eric. 1997. Los griegos y lo irracional, Madrid, Alianza.

Jung, Carl. 2003. Arquetipos e inconsciente colectivo, Barcelona, Paidós.

Konstan, David. 2001. Pity transformed, London, Duckworth, 2001.

Konstan, David. 2003. "Aristotle on anger and the emotions: The strategies of status", en Braund, Susanna and Most, Glenn W. (eds.), Ancient Anger: Perspectives from Homer to Galen, Yale Classical Studies 32, Cambridge, Cambridge University press, pp. 99-120. 
Konstan, David. 2003. "Before jealousy", en Konstan, Dvid and Rutter, Keith (edit.), Envy, Spite and jealousy, Edinburg, Edinburg University Press, pp. 7-27.

Konstan, David. 2004. "Las emociones en la antigüedad griega", en Pensamiento y cultura, $\mathrm{N}^{\circ} 7$, Sabana, pp. 47-54.

Lanata, Giuliana. 1966. "Sul linguaggio amoroso di Saffo", en Quaderni Urbinati di Cultura Classica, $\mathrm{N}^{\circ} 2$, Italia, pp. 63-79.

Le Goff, Jacques. 1999. La civilización de Occidente Medieval, Barcelona, Paidós.

Le Goff, Jacques. 1983. Tiempo trabajo y cultura en Occidente medieval, Madrid, Taurus.

Lutz, Catherine. 1988. Unnaturale Emotions: Everyday Sentiments on a Micronesian Atoll and Their Challenge to Western Theory, Chicago, University of Chicago Press.

Martínez, Marcos. 2010. Sófocles. Erotismo, Soledad, Tradición, Madrid, Clásicas.

Martínez, Marcos. 2012. "Erotismo en Homero (I)", en Cuadernos de Filología Clásica. Estudios griegos e indoeuropeos, $\mathrm{N}^{\circ} 22$, Madrid, pp. 53-72.

Mosse, Claude. 1990. La mujer en la Grecia clásica, Nerea, Madrid.

Mosse, Claude. 1991. Sapho de Lesbos, Amour et sexualité en occident, Paris, Seuil, Paris.

Pomeroy, Sarah. 1999. Diosas, rameras, esposas y esclavas: Mujeres en la antigüedad clásica, Madrid, Akal.

González, Francisco. 1996. "Mito e ideología: supremacía masculina y sometimiento femenino en el mundo griego antiguo", en González, Francisco, Bermejo, José, Reboreda, Susana, Los orígenes de la mitología griega, Madrid, Akal, Madrid, pp. 163-216.

Rodríguez, Adrados. 1996. Sociedad Amor y Poesía en la Grecia antigua, Madrid, Alianza.

Rodríguez, Adrados. 1995. Estudios de semántica y sintaxis, Barcelona, Planeta.

Rodríguez, Adrados. 1981. El mundo de la lírica griega antigua, Madrid, Alianza.

Rodríguez, Francisco. 1980. La lírica griega arcaica, (poemas corales y monódicos 700-300 a. C.) Madrid, Gredos.

Rosenwein, Bárbara. 2006. Emotional Communities in the Early Middle Ages, Ithaca, Cornell University Press.

Saavedra, Alejandro. 2018. El ideal de amor conyugal en la época arcaica, a través de las obras de Homero y Hesíodo. Universidad de Concepción, Tesis para optar al grado de Magister en Historia. Saavedra, Alejandro. 2020. "Un acercamiento al lenguaje del amor en las obras de Homero y Hesíodo", en Historias del orbis terrarum, №24, Santiago, pp. 8-31.

Schadewaldt, Wolfgang. 1936. "Zu Sappho", en Hermes 71, N³ 3, Alemania, pp. 363-373.

Schadewaldt, Wolfgang. 1973. Safo Mundo y poesía. Existencia en el amor, Buenos Aires, Eudeba. Séneca. 1989. Epístolas a Lucilo. Traducción y notas de Ismael Roca Mella, Madrid, Gredos.

Sternberg, Robert. 2000. El triángulo del amor: intimidad, pasión y compromiso, Madrid, Paidós. Suárez, Emilio. 2019. Antología de la lírica griega arcaica, Madrid, Cátedra.

Torres, José. 2019. Introducción a la literatura griega antigua, Síntesis, Madrid.

Vernant, Jean Pierre. 2001. El individuo la muerte y el amor en la antigua Grecia, Barcelona, Paidós. Vernant, Jean Pierre. 1993. El hombre griego, Madrid, Alianza. 
Vega, Irina. 2016. "Una aproximación al Thíasos lésbico desde la lírica de Safo", en Revista de estudios clásicos, $\mathrm{N}^{\circ} 43$, Cuyo, pp. 233-248.

Windschuttle, Keith. 1997. "The myths of Eros", reseña a "Eros: the myth of ancient greek sexuality" de Thornton Bruce, en Partisan Review, Fall, №4, Londres, pp. 656-665. 